\title{
Quantification of Household Food Waste in Hungary: A Replication Study Using the FUSIONS Methodology
}

\author{
Gyula Kasza ${ }^{1, *}$, Annamária Dorkó ${ }^{1}$, Atilla Kunszabó ${ }^{1}$ (D) and Dávid Szakos ${ }^{2}$ (D) \\ 1 Risk Management Directorate, National Food Chain Safety Office, 1024 Budapest, Hungary; \\ dorkoa@nebih.gov.hu (A.D.); kunszaboa@nebih.gov.hu (A.K.) \\ 2 Department of Veterinary Forensics and Economics, University of Veterinary Medicine Budapest, \\ 1078 Budapest, Hungary; szakos.david@univet.hu \\ * Correspondence: kaszagy@nebih.gov.hu; Tel.: +36-20-454-8418
}

Received: 15 March 2020; Accepted: 8 April 2020; Published: 11 April 2020

check for updates

\begin{abstract}
Household food waste accounts for the most significant part of total food waste in economically developed countries. In recent times, this issue has gained recognition in the international research community and policy making. In light of the Sustainable Development Goals of FAO, mandatory reporting on food waste has been integrated into European legislation, as a basis of preventive programs. The paper presents the results of research that aimed to quantify the food waste generated by Hungarian households. Research methodology was based on the EU compliant FUSIONS recommendations. In total, 165 households provided reliable data with detailed waste logs. Households were supported by kitchen scales, measuring glasses, and a manual. Based on the extrapolation of the week-long measurement, the average food waste was estimated to be $65.49 \mathrm{~kg}$ per capita annually, of which the avoidable part represented $48.81 \%$. Within the avoidable part, meals, bakery products, fresh fruits and vegetables, and dairy products are accountable for $88 \%$ of the mass. This study was a replication of the first Hungarian household food waste measurement conducted in 2016 with the same methodology. Between the two periods, a 4\% decrease was observed. The findings, for instance the dominant share of meals in food waste, should be put in focus during preventive campaigns. National level food waste measurement studies using the FUSIONS methodology should be fostered by policy makers to establish the foundations of effective governmental interventions and allow for the international benchmarking of preventive actions.
\end{abstract}

Keywords: household food waste; food waste measurement; food waste composition; sustainable consumption; consumer research; consumer behavior

\section{Introduction}

In recent times, food wastage has become a frequently investigated issue. In countries with developed economic status, the largest quantities of food waste are generated at the consumer level [1]. The ratio of household food waste in the EU is estimated to be about $53 \%$ of the amount produced within the entire food chain, which equals $92 \mathrm{~kg}$ per capita annually [2]. Reported numbers are mainly originating from calculations based on general waste databases of the member countries. In the last ten years, research activity has been accelerated in this field, delivering a variety of-sometimes contradictory - results. The greatest research activity in the field is focusing on Northern and Western Europe (prominently Denmark, Finland, Germany, Italy, Norway, UK) [3], but there are several examples outside the continent as well (USA, China, Canada) [4].

The majority of the variation in reported empirical data can be explained by the wide range of methods used by the studies. There are quite a few direct research methods that can be applied in 
research practice to acquire primary data on the extent of household food waste [5,6]. Several reports used questionnaires, where the focus is on self-reporting [7-10]. Physical measurements, such as diaries or composition analysis, are also widely used methods [11-17]. Nevertheless, we must take into consideration that these methods entail a great deal of uncertainty [18]. For instance, separately collected organic stream could contain other biological waste besides food (flowers, green waste from the garden or the street), while other elements could be missing (food put in general domestic waste, poured into the sink, or fed to animals) [19]. A significant gap can be detected between the amounts resulted from physical measurements and self-report surveys $[17,20,21]$. Self-reported numbers tend to be significantly lower than physically measured values. Physical measurements, however, require a serious commitment from family members and a great amount of trust invested in the researchers. Moreover, gathering an appropriate sample size in physical measurement surveys is a very challenging endeavor. Despite the known hindrances of the discussed research methods, it must be noted that acquiring reliable and detailed information on household food waste is of great importance [22]. A recent study argues that physical measurements for data collection instead of self-reporting are preferred [23], because of their higher reliability.

In the case of Hungary, the only study based on the physical measurement of household food waste was conducted in 2016 [24]. The measurement involved 100 households during a one-week period. Besides solid food items, liquid waste was also measured, which was later considered to be an essential element of food waste accounting [6]. Based on the results of this study, $68.04 \mathrm{~kg}$ of food were wasted in average by a Hungarian person annually, and out of it $33.14 \mathrm{~kg}$ would have been avoidable. Similar results have been found by a Greek study, involving 101 urban households [15]. After the 14-day measurement period, the assessment of the total per capita food waste resulted in $76.1 \mathrm{~kg}$, of which $25.9 \mathrm{~kg}$ considered as avoidable. The proportion of the avoidable part was proven to be relevant in Finland too, $23 \mathrm{~kg}$ per person annually [12]. The differentiation between avoidable and unavoidable food waste is recommended and applied in the vast majority of measurements $[11,12,16,17,23,25,26]$.

The composition of household food waste varies from country to country. However, it is found that generally the most perishable food items are thrown away the most frequently [27]. With respect to the avoidable category, these food items include fresh fruits and vegetables, bakery products, and dairy products. According to the previous Hungarian study, the main types were meals, bakery products, fresh vegetables, dairy products, and fresh fruits [24]. In Serbia, though in reverse order, bakery products and ready-to-eat food items were on the top of the list as well [28]. Bread and bakery products were observed to have the highest ratio in Norway as well, based on a waste composition analysis [14]. Contrastively, fresh vegetables and drinks have been found to be the most prevalent types in the UK [11]. Vegetables were observed to be the most commonly wasted food items in Denmark, Greece, and Israel $[13,15,16]$.

In order to reach the Sustainable Development Goal 12.3, halving the amount of food waste by 2030 [29], it would be essential to determine the magnitude of the problem that we face. According to a recent study, $15-16 \%$ of the total environmental impact of the food supply chain is derived from food waste [30]. It can also be stated that food wastage is in constant increase (especially in developed countries), and the actual quantity of food waste seems to be twice the amount of the results from previous global estimates [31]. Physical measurements, especially in households-a sector that accounts for the most significant part of food waste in the food chain-play a central role in refining national statistics [24]. However, this poses a particular challenge, since the lifestyle, consumption trends, and purchasing habits are in continuous change [32].

Recently, the importance of food waste measurement has become a major concern also at the European Union legislative level. Until 2020, the member states have to integrate a food waste reduction strategy into the national waste reduction plan. Furthermore, food waste prevention campaigns have to be established at the national level [33]. The European Commission has recently issued a decision establishing a common methodology and determining the minimum quality requirements for food waste data collection $[34,35]$. The national food waste reduction strategies should be based on the 
actual numbers, which have to be updated every four years. Measures aiming at food waste reduction may pose an elevated health risk to consumers (for instance eating expired food or offering it to charity, feeding potentially infectious food to livestock or companion animals). Therefore, communication campaigns, governmental institutions, and business organizations should handle food safety questions as a priority during food waste reduction efforts [36].

The aim of this research was to estimate the amount of food waste that an average Hungarian household generates based on a one-week period. This investigation was a replication of a household food waste measurement conducted in 2016 with the same methodology, within the boundaries of the Wasteless (Maradék nélkül) food waste prevention campaign, organized by the National Food Chain Safety Office in Hungary.

\section{Materials and Methods}

\subsection{Theoretical Background}

Household food waste measurement is an important step in the global efforts to reduce food losses [37]. However, a sound theoretical background, experience in practical organization, and comparable research data are scarce in this field. From the 1990s, a methodological evolution can be observed in this field, which allowed us to apply a standardized research methodology in 2016 and in our actual study (Figure 1).

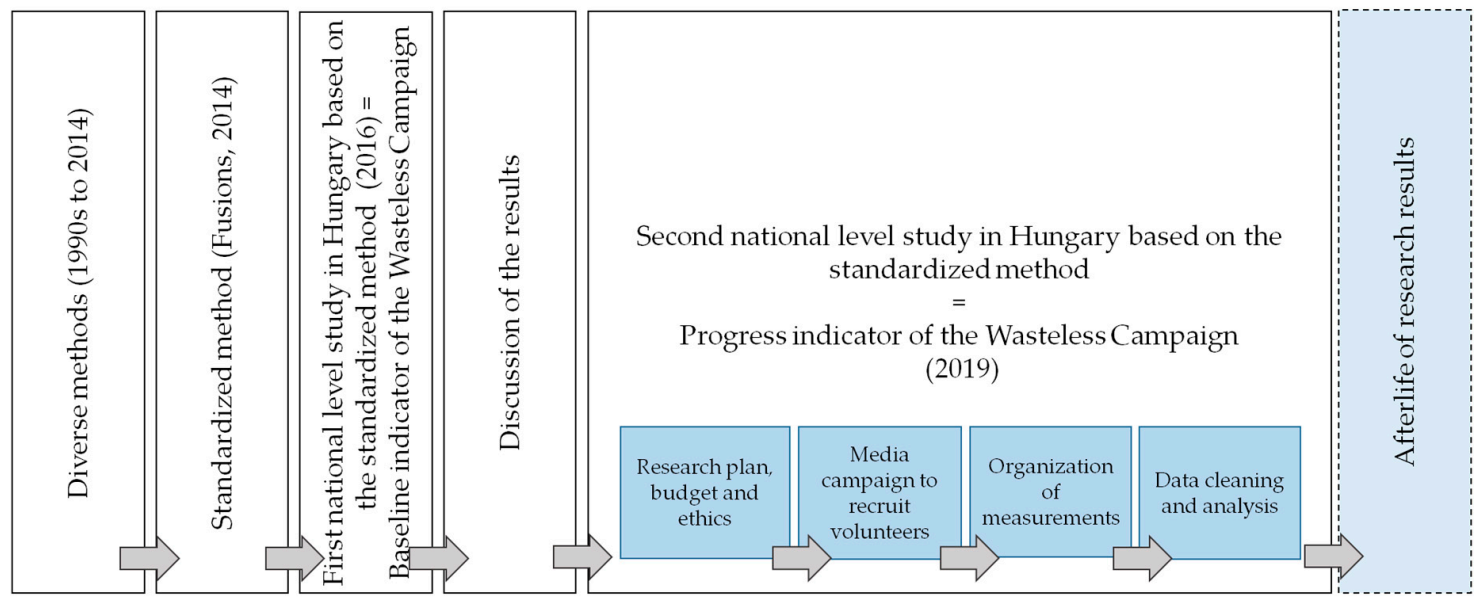

Figure 1. Theoretical framework and organization of the study.

\subsubsection{Diverse Methods (1990s to 2014)}

Despite the growing number of studies carried out to investigate the quantity of household food waste, the diversity of methodological approaches that different researchers applied limited the comparability of most of the findings, dating back to the 1990s [18], which might have resulted in different interpretations of the research data. The following methods were used most frequently [38]:

- Questionnaire-based survey

- Food waste diary

- Waste composition analysis

- Interview

- Mass and energy balance

- Statistics from authorities or waste management companies

Besides the basic methodological approach itself, a further significant bias resulted from small differences in the considerations applied by the research teams. For instance, the recorded material streams and their classification were also divergent. Typical differences found in the literature: 
- Inedible part of foodstuffs are recorded / not recorded [3]

- Differences in the definition of the avoidable (in some studies: edible) food waste category [16]

- Potentially avoidable food waste is classified / not classified as an individual category [26]

- $\quad$ Liquids are measured / not measured $[12,15,17]$

- Food waste going to a valorization stream (e.g., composting, feed) are not recorded / recorded [5, 12,17]

- Food made for human consumption but ultimately fed to animals is classified / not classified as food waste [39]

- The part of food eaten that exceeds physiological nutritional needs of a person is recorded / not recorded as food waste [40]

- Food packaging is recorded / not recorded [41]

- Different measurement tools and units that could not be reliably converted to mass units $[42,43]$

- Different observation units (e.g., per person, per household) [13-15,17,20,24]

\subsubsection{Standardized Method (FUSIONS, 2014)}

Considering these barriers, the FUSIONS project, funded by the European Commission recognized the importance of establishing a standard for measurement methodology. Between 2012 and 2016, FUSIONS consulted researchers, industrial stakeholders, and governments about the harmonization of food waste monitoring. One of the most significant deliverables of FUSIONS was a well-balanced, widely accepted standardized methodology (that we refer to as FUSIONS methodology) to measure food waste [38], which provides the opportunity to compare country-level data. The most important considerations for household food waste measurement studies, according to the FUSIONS methodology, are the following:

- Food waste should be recorded in a diary by household members

- A description of the food or drink waste should be given in the diary

- The amount of waste should be measured and recorded

- Throughout the fieldwork, it is suggested that the researcher maintains regular contact with each household to resolve any issues, encourage participation, and ensure the accurate completion of the diary

- The sample needs to include at least a few hundred households

\subsubsection{First National-Level Study in Hungary Based on the FUSIONS Methodology}

In 2015 the National Food Chain Safety Office of Hungary (Nébih) started a public awareness campaign on household food waste prevention, called "Wasteless", which received support in 2016 from the LIFE Framework program of the EU. Influential European food waste prevention projects were: the EU-FP7 funded FUSIONS and Horizon 2020 funded "Refresh", the "Love Food Hate Waste" campaign by WRAP, and the "Every Crumb Counts" campaign organized by different entities from the industry, academics, and NGOs. Wasteless aimed to decrease avoidable food waste in Hungarian households. In order to measure the efficiency of the communication efforts, a baseline was set based on the FUSIONS recommendations. This has been the first empirical study carried out with this methodology in the Central and Eastern European region [24]. Focus group interviews and a preliminary, representative quantitative consumer survey covering 1000 respondents were conducted to receive research insights before the first household study.

\subsubsection{Discussion of the Experiences of the First Study}

The results of the survey were published in national and international academic journals and discussed at national and international platforms (including the EU Platform on Food Losses and Food Waste, operated by the Directorate-General for Health and Food Safety of the EU Commission) 
and scientific conferences [24,37,44-47]. Public dissemination activities through the Wasteless communication campaign were also conducted, presenting the results to consumers. Until 2018 the campaign managed to achieve a reach of almost 50 million via different media platforms [37], and the research results are widely cited by journalists even today.

\subsubsection{Second National-Level Study in Hungary Based on the FUSIONS Methodology}

A second study for household food waste measurement using the FUSIONS methodology took place in 2019. The research was organized to deliver comparable data to monitor changes in food waste quantities and composition. According to the analysis of the literature, this study has most probably been the first one to repeat a previous measurement based on the FUSIONS methodology. Although the research was not conducted as a validation action, its experiences are still valuable to indicate the replicability of the methodology.

The research was advertised in a media campaign in October 2019. The households were selected on the basis of voluntary registration. The advertisement included radio interviews (6); television interviews (3); press releases (7); online press releases (45). In total, 200 households applied to participate in the research. The sampling was conducted in November and December of 2019. The sampling period avoided all national and religious holidays.

During the measurement period, households received a kitchen scale (accuracy in grams) and a measuring glass from the research team. The measuring glass served for liquid wastes. Participants were also provided with a manual which described the scope of the research and explained clearly the difference between avoidable and unavoidable food waste. The following definitions were used for avoidable, unavoidable, and potentially avoidable food waste [11]:

- Avoidable—food and drink thrown away that was, at some point prior to disposal, edible (e.g., slice of bread, apples, meat)

- Unavoidable - waste arising from food or drink preparation that is not, and has not been, edible under normal circumstances (e.g., meat bones, egg shells, pineapple skin, tea bags)

- Potentially avoidable: food and drink that some people eat and others do not (e.g., bread crusts), or that can be eaten when a food is prepared in one way but not in another

For the whole duration of the investigation, e-mail and telephone support was provided to the participants. Attention was paid to reduce bias by explaining participants that the data collection was conducted anonymously, which impeded the identification of the household. The data was administered into a unified waste log. Participating households could use an online platform or a printed sheet for this purpose. The weight and exact type of each unit of food waste had to be recorded for one week (seven days). This time frame is assumed to be long enough to reduce influences caused by the participants' compulsion to conform, originating from the fact of observation. Data on solid and liquid waste were documented in mass (grams). Weighing had to be performed prior to disposal.

A supporting unit was set up to help participants of the household measurement study taking care of:

- $\quad$ Procurement of the tools for the measurement (scales and measuring glasses)

- Compilation of the questionnaire and log-book structure, maintaining the online platform for online data registration, and printing the hard copy version of the diary

- Receiving volunteer applications and answering the questions of the prospective households

- Distributing measurement tools, guides, and diaries to the participants

- Operating a call center for the participants to resolve any issues that arose during the measurement

- Online messages to keep contact with participants and maintain motivation

A total of 200 households applied for participation in the survey during the media campaign, but only 165 households provided a reliable and complete data set for the analysis. The most common reasons for excluding households were interrupted communication, logs not returned by 
the participants, an inappropriate or non-consecutive data recording period, missing data in the logs, or inadequate details on food types that made the classification impossible.

Although there have been several studies on the topic with similar or even smaller sample sizes $([15] n=101 ;[16] n=192 ;[19] n=61 ;[41] n=61 ;[48] n=13)$, a post-hoc calculation was performed to determine the power of the test, for which data from the previous Hungarian study [24] served as basis. The power of the test proved to be $87.5 \%$, which meets the criterion of being above $80 \%$ [49-51].

Based on the household data, a detailed classification was made by the research team (e.g., meals, bakery products, fresh vegetables, etc.). Each item had to be recorded by the participants as accurately as possible (e.g., not 'bread' but 'bread crust', not 'chicken' but 'chicken skin', etc.). Avoidable and unavoidable food waste units were recorded separately by the households. Subsequently to the measurement, the research team conducted a post-hoc validation of the categorization performed by the consumers.

After data cleaning, the analysis was conducted for each household. Data on food waste per person were calculated in each food waste category. The results were extrapolated to one year by multiplying the results of the one week by 52 .

\subsubsection{Afterlife of Research Results}

Planning the afterlife of the research data has been a part of the theoretical framework. This inspection is considered to be an element in a time series study, with the objective of providing information to policy makers on a regular basis and also helping to optimize public awareness-raising activities. Since the reporting on the food waste situation became a compulsory activity of all EU member states [35], the study will also serve to deliver national level data to the EU Commission with respect to Hungarian households. Experiences with the FUSIONS methodology are still scarcely available, and therefore sharing the findings of this research may help other research teams to start their own activities in this field.

\subsection{Sample Description}

The socio-demographic characteristics were collected by an initial questionnaire at the households (Table 1). This characterization covered the geographical location, the size and level of income of the household, and the age, sex, and qualification of the respondent. The income level of the household had to be estimated subjectively by the inhabitants, compared to the average income level in Hungary. A total of 200 households applied, and 165 households provided appropriate data sets. These 165 households represented 452 consumers in total.

Table 1. Socio-demographic composition of the sample.

\begin{tabular}{cc}
\hline Sex of respondents generally responsible for food purchasing & Sample \\
\hline Female & $83.03 \%$ \\
Male & $16.97 \%$ \\
\hline Regions (NUTS1) & \\
\hline Central Hungary & $42.42 \%$ \\
Transdanubia & $32.73 \%$ \\
Great Plain and North & $24.85 \%$ \\
\hline Geographical location & \\
\hline Capital city (Budapest) & $27.88 \%$ \\
$\quad$ Other city & $55.76 \%$ \\
Village & $16.36 \%$ \\
\hline
\end{tabular}


Table 1. Cont.

\begin{tabular}{cc}
\hline Household size & \\
\hline 1 & $13.94 \%$ \\
2 & $33.94 \%$ \\
3 & $26.06 \%$ \\
4 & $17.58 \%$ \\
$\geq 5$ & $8.48 \%$ \\
Average household size & 2.7 people \\
\hline Age of the person generally responsible for food purchasing & \\
\hline Under 30 years & $11.52 \%$ \\
Between 30 and 39 years & $20.61 \%$ \\
Between 40 and 59 years & $50.91 \%$ \\
Above 60 years & $16.97 \%$ \\
\hline Qualification of the person generally responsible for food & \\
purchasing & $6.0 \%$ \\
\hline Elementary & $38.2 \%$ \\
High school graduation & $61.2 \%$ \\
Higher education & $1.21 \%$ \\
\hline Income level of the household & $14.55 \%$ \\
\hline Low & $65.45 \%$ \\
Below average & $16.97 \%$ \\
Average & $1.82 \%$ \\
\hline Above average & \\
Very high & \\
\hline
\end{tabular}

Number of households: 165; Total participants: 452.

\section{Results}

During the measurement period, the 165 participant households generated $532.76 \mathrm{~kg}$ of food waste (Table 2). After extrapolation of the one week data per capita, the total per capita food waste was estimated to be $65.49 \mathrm{~kg}$ annually (Table 3).

Table 2. Quantity of food waste categories.

\begin{tabular}{cccc}
\hline \multirow{2}{*}{ Food Waste Categories } & \multicolumn{2}{c}{ Amount of Waste of $\mathbf{1 6 5}$ Households during the One-Week Period (kg) } \\
\cline { 2 - 4 } & Solid & Liquid & Total = Solid + Liquid \\
\hline Unavoidable food waste & 239.33 & 7.19 & 246.52 \\
Potentially avoidable food waste & 17.40 & 3.27 & 20.67 \\
Avoidable food waste & 218.27 & 47.29 & 265.56 \\
\hline Total food waste & 475.00 & 57.75 & 532.75 \\
\hline
\end{tabular}

Table 3. Estimation of annual household food waste generation per capita.

\begin{tabular}{cccc}
\hline \multirow{2}{*}{ Food Waste Categories } & \multicolumn{2}{c}{ Extrapolated Data for One Year per Capita (kg) } \\
\cline { 2 - 4 } & Solid & Liquid & Total = Solid + Liquid \\
\hline Unavoidable food waste & $29.91(51.08 \%)$ & $0.90(12.99 \%)$ & $30.81(47.04 \%)$ \\
Potentially avoidable food waste & $2.30(3.93 \%)$ & $0.42(6.06 \%)$ & $2.72(4.16 \%)$ \\
Avoidable food waste & $26.35(45.00 \%)$ & $5.61(80.95 \%)$ & $31.97(48.81 \%)$ \\
\hline Total food waste & $58.56(100.00 \%)$ & $6.93(100.00 \%)$ & $65.49(100.00 \%)$ \\
\hline
\end{tabular}

The proportion of the avoidable fraction (which means the real wastage) was the highest, with $48.81 \%$ ( $31.97 \mathrm{~kg}$ annually) of the total food waste. The unavoidable food waste category 
accounted for $47.04 \%$ (30.81 kg annually). The most prevalent food types within this category were coffee grounds, inedible fruit and vegetable parts (inedible peels such as banana peels, citrus fruit peels, onion peels, and inedible stalk, woody parts, seeds, shell of nuts, etc.), bones, eggshell, and teabags. The potentially avoidable part, such as edible fruit and vegetable peels (e.g., apple, pear, cucumber, tomato, mushroom, zucchini), chicken skin, bread crust, greasy pieces of meat, pickling liquid, juices of canned food, and oil of canned fish represented the smallest proportion, with $4.16 \%$ ( $2.72 \mathrm{~kg}$ annually). Liquid food, such as soft drinks, coffee, tea, and soup appeared in the logs in significantly lower amounts compared to solid foodstuffs (Table 3).

Eighteen different food categories were defined based on the recorded elements within avoidable food waste. Results suggest that consumers discard perishable foodstuffs more frequently and in larger quantities than durable products. Table 4 shows the mass and proportion of the established food waste categories.

Table 4. Quantity and proportion of food categories within avoidable food waste based on the one-week measurement in 165 households.

\begin{tabular}{ccc}
\hline Avoidable Food Waste & Total Weight & Proportion (\%) \\
\hline Meals (home-made and ready-to-eat) & 118.80 & 44.74 \\
Bakery products & 46.79 & 17.62 \\
Fresh vegetables & 26.55 & 10.00 \\
Dairy products & 21.12 & 7.95 \\
Fresh fruits & 20.03 & 7.54 \\
Mineral water, soft drinks, coffee, tea & 6.93 & 2.61 \\
Canned foods, pickles & 5.37 & 2.02 \\
Processed animal products & 4.77 & 1.80 \\
Grain products (flour, semolina, oat) & 4.25 & 1.60 \\
Raw meat & 4.06 & 1.53 \\
mayonnaise) & 2.87 & 1.08 \\
Marmalades, jams & 1.37 & 0.52 \\
Confectionery, snacks & 1.20 & 0.45 \\
Eppings (ketchup, mustard dressings) & 0.77 & 0.29 \\
Yeast, muesli, corn flakes, raisins, puffed rice, baking mixtures & 0.49 & 0.19 \\
Frozen meats, vegetables & 0.10 & 0.04 \\
Fats (butter, margarine, lard, etc.) & 0.08 & 0.03 \\
Packed spices (rosemary, marjoram, parsley, etc.) & 0.01 & 0.01 \\
\hline Total & 265.56 & 100.00 \\
\hline
\end{tabular}

Meals (including homemade and ready-to-eat) account for the highest proportion (44.74\%) of the total avoidable food waste. Bakery products (typically breads and bread rolls) are the second most common food items in this category (17.62\%). Fresh vegetables and fresh fruits have also significant proportions, $10.00 \%$ and $7.54 \%$, respectively. Dairy products ranked in the fourth place of the list (7.95\%). These five product categories altogether represent almost $88 \%$ of the total avoidable food waste.

Based on the actual data collected from the households, the quantity of annual avoidable wastage in the particular food categories has been estimated with extrapolation (Figure 2). 


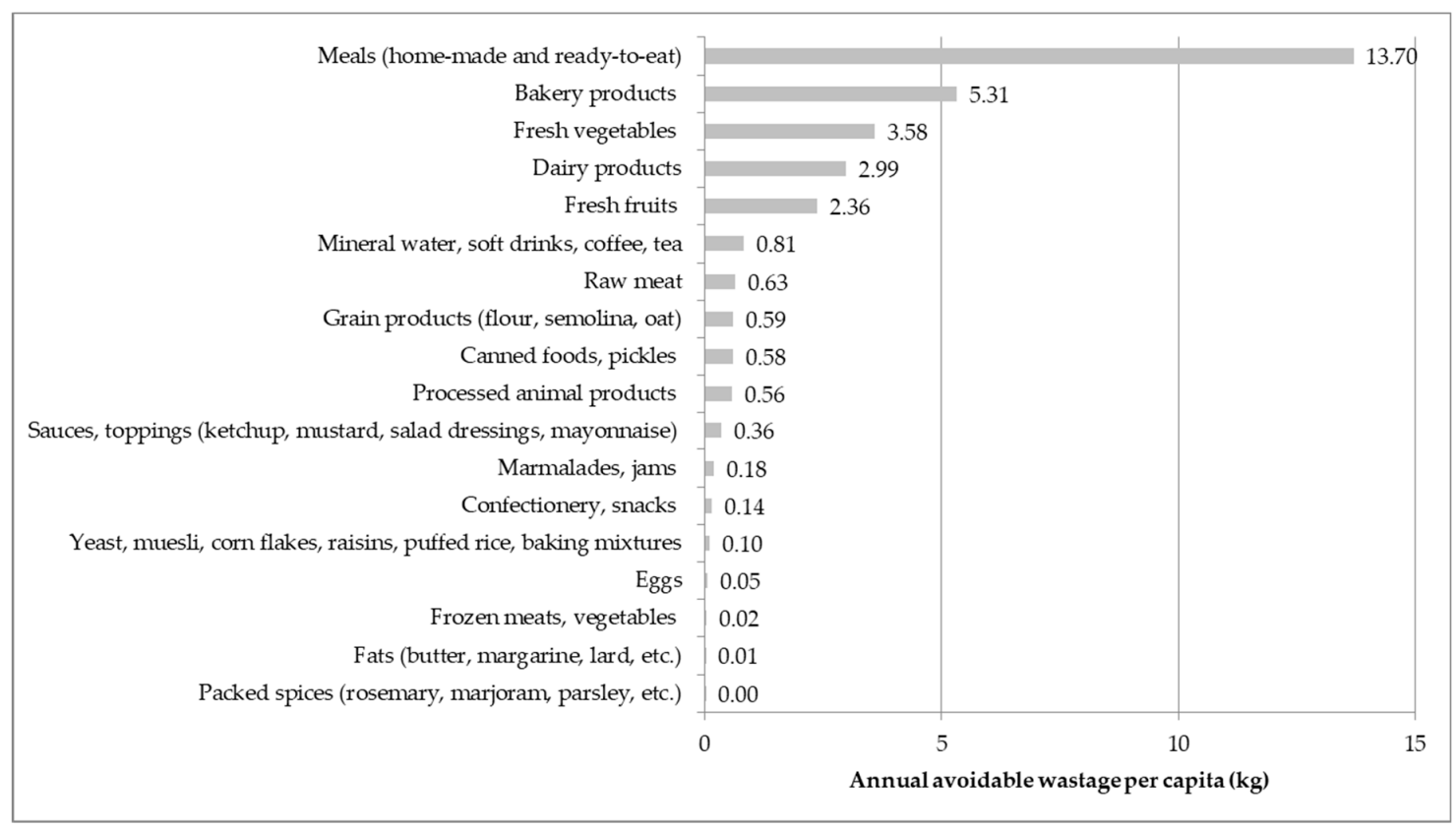

Figure 2. Annual avoidable wastage in different food categories per capita.

\section{Discussion}

Due to the role of consumers in food wastage in economically developed countries, gathering actual data on food waste generation from households is a major issue and a prerequisite for successful prevention campaigns [22]. Since the reliability of physical measurements is higher [23], our research placed the focus on determining the exact quantities of food waste that Hungarian households generate. The study illustrates several similarities and also some contradictions when compared to the international literature.

The actual study is a replication of the first Hungarian measurement-based research conducted in 2016 [24], which we regarded as a baseline for comparison. A decrease of $4 \%$ in the annual food waste per capita estimation was observed between the two periods $(65.49 \mathrm{~kg}$ compared to $68.04 \mathrm{~kg}$ from 2016). The constitution of food waste in the households was found to be very similar, indicating a dominant rate of avoidable food waste (an actual share of $48.82 \%$ compared to $48.70 \%$ in 2016 ), followed by the unavoidable part (47.05\% compared to $47.13 \%$ in 2016). Potentially avoidable food waste remained under $5 \%$ in both periods. (Table 5). Although the second household food waste measurement study was not organized and not suitable to be a validation of the replicability of the FUSIONS methodology [38], the results suggest that it might deliver reliable data for decision makers.

Table 5. Proportion of food waste categories (actual data compared to the findings of the 2016 study [24]).

\begin{tabular}{ccc}
\hline Food Waste Categories & $\mathbf{2 0 1 9}$ & $\mathbf{2 0 1 6}$ \\
\hline Unavoidable food waste & $47.05 \%$ & $47.13 \%$ \\
Potentially avoidable food waste & $4.15 \%$ & $4.16 \%$ \\
Avoidable food waste & $48.82 \%$ & $48.70 \%$ \\
\hline Total food waste & $\mathbf{1 0 0 . 0 0 \%}$ & $\mathbf{1 0 0 . 0 0 \%}$ \\
\hline
\end{tabular}

As already discussed, a number of methodological differences can be observed in the international literature that limits the comparability of the studies $[16,26]$. The proportion of avoidable food waste observed by the two Hungarian studies is higher than in Greece, where $25.9 \mathrm{~kg}$ from the total $76.1 \mathrm{~kg}$ household food waste $(n=101)$ was reported based on the diary method [15]. In Finland, a significantly lower amount of avoidable food waste was also found (23 kg in total) [12]. Similarly, a lower proportion 
$(35 \%)$ of avoidable waste was noted in Sweden, as a result of a waste composition analysis with 486 households [52], in which the number of individual consumers remained unknown. The differences might partially be explained by the fact that the Hungarian studies have also recorded liquids besides solid food waste, and their contribution to the avoidable part was found to be significant. However, an Italian study - applying the diary method with 388 families—demonstrated that a person generates $27.5 \mathrm{~kg}$ of avoidable food waste annually in Italy, including liquids [17]. They also pointed out that, based on the studies that they had reviewed, the average mass of edible food waste was between 27.5 and $33 \mathrm{~kg}$. The diary method was also employed in the UK, in a one-week measurement survey involving 13 households [48]. The study revealed that the total measured food waste (including liquids) was $0.199 \mathrm{~kg}$ per person per day. This would be equal to $72.63 \mathrm{~kg}$ annually, which is higher, but still similar to our results. In Israel $573 \mathrm{~g} /$ day per capita of food waste was measured involving 192 households, based on a new method of physical measurement [16]. Scaling up this outcome to one year, we would get $209 \mathrm{~kg}$, which is much higher compared to the above-mentioned studies. A further hindrance to comparing international food waste research data are the units that researchers use to present their results. While some studies-including the present paper-provide the amount of generated food waste "per person" [12,15-17,48], others presented their results "per household" [13,14,17,20,41]. The one-week long household food waste measurement study in Israel, applying waste sorting analysis, resulted in $3.012 \mathrm{~kg}$ avoidable food waste per household per week (without liquids) [20]. In Denmark, the outcomes of a waste composition analysis (involving 1474 households) showed that a household generates $183 \mathrm{~kg}$ of food waste, of which the avoidable food waste was $103 \mathrm{~kg}$ per household per year [13].

Parfitt et al. made the general observation that perishable food items are the most frequently discarded ones [27], which has been confirmed by this paper as well. Results indicate that meals, bakery products, fresh vegetables, dairy products, and fresh fruits are the most frequently discarded food types within the avoidable part. This also correlates with the outcomes of the first Hungarian study [24], which indicated the same order. However, the share of meals appeared to be higher (44.73\%) than in the previous study $(40.08 \%)$, which suggests that Hungarian consumers' cooking habits and leftover storage practices should be addressed in food waste prevention awareness campaigns. Similarly to our study, bakery products and ready-to-eat food items were found to be the most prevalent food waste types in Serbia [28]. In contrast, fresh vegetables were on the top of the list in the UK, Greece, Denmark, and Israel $[11,13,15,16,52]$. The discovered differences in the composition of household food waste may be explained by the eating habits of different nations. It has been assumed that the season when the survey period is conducted also affects the composition of discarded food types [24].

Concerning the limitations of the general interpretation of the data, it has to be mentioned that the recruitment of households was challenging, as well as achieving participant engagement and constant activity, even for a period as short as seven days. An additional potential source of error is the fact that, since the research team was not capable of offering a financial incentive, enthusiastic participants with a more conscious behavior regarding food handling were more likely to get involved in the study [12]. However, we assume that the other family members compensated this behavior to some extent. Furthermore, in the measurement period, participants might have changed their general wasting behavior and become more conscious, knowing that they were being observed, which could have resulted in lower amounts of weighed total food waste [15]. It could also have happened that, due to the compulsion to conform, originating from the fact of observation, some participants did not record all of the discarded food items. On the other hand, the duration of the survey could be long enough to alleviate this phenomenon to some extent. An additional limitation of the study was that income level is difficult to assess, compared to other socio-demographic parameters [53]. Asking the respondents' income directly would have been indiscreet, and therefore a subjective ordinal scale was applied in the questionnaire. All of the mentioned limitations could result in an underestimation of the actual food waste amount generated in the household. However, by the application of the 
standardized methodology developed by FUSIONS, research data from different countries could be compared, and the possibility to observe tendencies in the different countries was also provided.

The importance of a common methodology is especially highlighted by the recent changes in EU legislation. According to the latter, all member states should conduct food waste measurements in the food chain covering agriculture, food processing, retail, catering, and households from 2020. Considering the major contribution of households to the total food waste production, this subject is expected to be a focus area in most of the countries during the next years. The EU Platform on Food Losses and Food Waste made the recommendation that in implementing national strategies to prevent food waste, member states should make full use of the latest findings of behavioral science research [37]. The experiences of the first academic studies in this field have certainly provided important input for the officers responsible for national level food waste measurements and preventive campaigns. Even more importantly, time series studies will help decision makers and communication experts to measure the performance of public awareness campaigns within a few years.

As a conclusion, the results of this research point out that a very significant part of food waste could be avoided. It is too early to reliably estimate the results of public campaigns before having longer time series data, but the first replication study using the FUSIONS methodology provided promising results. The $4 \%$ drop in avoidable food waste in a three-year period is notable, especially in a period of economic expansion. However, the fact that the list is still dominated by meals (incorporating the highest level of energy and natural resources amongst all food types) suggests that future public awareness campaigns should aim at this subject more efficiently.

Based on the results, some policy recommendations could be also formulated. Fostering national-level food waste measurement research with standardized methodologies is essential to establish the fundamentals of effective governmental interventions and to allow for the international benchmarking of preventive actions. It is also clear that food waste is a problem, which will persist for a long period in developed countries. A very intense campaign, which was observed in Hungary between the dates of the two studies, could contribute to a $4 \%$ drop in food waste, with all its novelty to society. While awareness raising should be continued, a major effort has to be placed on the integration of food waste prevention principles into children education. To be sure, we will never reach a zero level of avoidable food waste, but changing the habits of the new generation of food consumers can bring profound and long-lasting changes.

Author Contributions: G.K. and D.S. conceived the study; A.D. contributed to the data curation and formal analysis; G.K. contributed to funding acquisition; A.D. and A.K. contributed to the investigation, G.K. and D.S. contributed to the methodology and the supervision; G.K., A.D., and A.K. wrote the original draft; D.S. contributed to the review and editing of the manuscript. All authors have read and agreed to the published version of the manuscript.

Funding: The research was funded by the European Union's LIFE programme (LIFE15 GIE/HU/001048 project of the National Food Chain Safety Office of Hungary).

Conflicts of Interest: The authors declare no conflicts of interest.

\section{References}

1. Food and Agricultural Organization. Global Food Losses and Food Waste. 2011. Available online: http://www.fao.org/3/a-i2697e.pdf (accessed on 14 February 2020).

2. FUSIONS. Estimates for European Food Waste Level. 2016. Available online: https://www.eufusions.org/ phocadownload/Publications/Estimates\%20of\%20European\%20ood\%20waste\%20levels.pdf (accessed on 14 February 2020).

3. Schneider, F. Review of food waste prevention on an international level. Waste Res. Manag. 2013, 166, 187-203. [CrossRef]

4. Do Carmo Stangherlin, I.; de Barcellos, M.D. Drivers and barriers to food waste reduction. Br. Food J. 2018, 120, 2364-2387. [CrossRef]

5. Quested, T.E.; Parry, A.D.; Easteal, S.; Swannell, R. Food and drink waste from households in the UK. Nutr. Bull. 2011, 36, 460-467. [CrossRef] 
6. Corrado, S.; Caldeira, C.; Eriksson, M.; Hanssen, O.J.; Hauser, H.E.; van Holsteijn, F.; Liu, G.; Östergren, K.; Parry, A.; Secondi, L.; et al. Food waste accounting methodologies: Challenges, opportunities, and further advancements. Glob. Food Secur. 2019, 20, 93-100. [CrossRef]

7. Jorissen, J.; Priefer, C.; Brautigam, K.R. Food waste generation at household level: Results of a survey among employees of two European research centers in Italy and Germany. Sustainability 2015, 7, 2695-2715. [CrossRef]

8. Lorenz, B.A.S.; Hartmann, M.; Langen, N. What makes people leave their food? The interaction of personal and situational factors leading to plate leftovers in canteens. Appetite 2017, 116, 45-56. [CrossRef]

9. Ponis, S.T.; Papanikolaou, P.A.; Katimertzoglou, P.; Ntalla, A.C.; Xenos, K.I. Household food waste in Greece: A questionnaire survey. J. Clean. Prod. 2017, 149, 1268-1277. [CrossRef]

10. Stefan, V.; van Herpen, E.; Tudoran, A.A.; Lähteenmäki, L. Avoiding food waste by Romanian consumers: The importance of planning and shopping routines. Food Qual. Prefer. 2013, 28, 375-381. [CrossRef]

11. Quested, T.; Johnson, H. Household Food and Drink Waste in the UK; Final Report. WRAP: Banbury, UK, November 2009. Available online: www.wrap.org.uk/sites/files/wrap/Household_food_and_drink_waste_i n_the_UK_-_report.pdf (accessed on 14 February 2020).

12. Koivupuro, H.K.; Hartikainen, H.; Silvennoinen, K.; Katajajuuri, J.M.; Heikintalo, N.; Reinikainen, A.; Jalkanen, L. Influence of socio-demographical, behavioural and attitudinal factors on the amount of avoidable food waste generated in Finnish households. Int. J. Consum. Stud. 2012, 36, 183-191. [CrossRef]

13. Edjabou, M.E.; Petersen, C.; Scheutz, C.; Astrup, T.F. Food waste from Danish households: Generation and composition. Waste Manag. 2016, 52, 256-268. [CrossRef]

14. Hanssen, O.J.; Syversen, F.; Stø, E. Edible food waste from Norwegian households—Detailed food waste composition analysis among households in two different regions in Norway. Resour. Conserv. Recycl. 2016, 109, 146-154. [CrossRef]

15. Abeliotis, K.; Lasaridi, K.; Boikou, K.; Chroni, C. Food waste volume and composition in households in Greece. Glob. Nest J. 2019, 21, 399-404. [CrossRef]

16. Elimelech, E.; Ofira, A.; Eyal, E. What gets measured gets managed: A new method of measuring household food waste. Waste Manag. 2018, 76, 68-81. [CrossRef]

17. Giordano, C.; Alboni, F.; Falasconi, L. Quantities, determinants, and awareness of households' food waste in Italy: A comparison between diary and questionnaires quantities. Sustainability 2019, 11, 3381. [CrossRef]

18. Bräutigam, K.R.; Jörissen, J.; Priefer, C. The extent of food waste generation across EU-27: Different calculation methods and the reliability of their results. Waste Manag. Res. 2014, 32, 683-694. [CrossRef]

19. Parizeau, K.; von Massow, M.; Martin, R. Household-level dynamics of food waste production and related beliefs, attitudes, and behaviours in Guelph. Ontario. Waste Manag. 2015, 35, 207-217. [CrossRef]

20. Elimelech, E.; Ert, E.; Ayalon, O. Exploring the Drivers behind Self-Reported and Measured Food Wastage. Sustainability 2019, 11, 5677. [CrossRef]

21. Van Herpen, E.; van der Lans, I.A.; Holthuysen, N.; Nijenhuis-de Vries, M.; Quested, T.E. Comparing wasted apples and oranges: An assessment of methods to measure household food waste. Waste Manag. 2018, 88, 71-84. [CrossRef]

22. Corrado, S.; Sala, S. Food waste accounting along global and European food supply chains: State of the art and outlook. Waste Manag. 2018, 79, 120-131. [CrossRef]

23. Schanes, K.; Dobernig, K.; Gözet, B. Food waste matters-A systematic review of household food waste practices and their policy implications. J. Clean. Prod. 2018, 182, 978-991. [CrossRef]

24. Szabó-Bódi, B.; Kasza, G.; Szakos, D. Assessment of household food waste in Hungary. Br. Food J. 2018, 120, 625-638. [CrossRef]

25. Schneider, F.; Obersteiner, G. Food waste in residual waste of households-Regional and socio-economic differences. In Proceedings of the Eleventh International Waste Management and Landfill Symposium, Sardinia, Italy, 1-5 October 2007; pp. 469-470.

26. Lebersorger, S.; Schneider, F. Discussion on the methodology for determining food waste in household waste composition studies. Waste Manag. 2011, 31, 1924-1933. [CrossRef]

27. Parfitt, J.; Barthel, M.; MacNaughton, S. Food waste within food supply chains: Quantification and potential for change to 2050. Philos. Trans. R. Soc. B Biol. Sci. 2010, 365, 3065-3081. [CrossRef]

28. Djekic, I.; Miloradovic, Z.; Djekic, S.; Tomasevic, I. Household food waste in Serbia-Attitudes, quantities and global warming potential. J. Clean. Prod. 2019, 229, 44-52. [CrossRef] 
29. United Nations. Transforming Our World: The 2030 Agenda for Sustainable Development; United Nations: New York, NY, USA, 2015.

30. Scherhaufer, S.; Moates, G.; Hartikainen, H.; Waldron, K.; Obersteiner, G. Environmental impacts of food waste in Europe. Waste Manag. 2018, 77, 98. [CrossRef]

31. van den Bos Verma, M.; de Vreede, L.; Achterbosch, T.; Rutten, M.M. Consumers discard a lot more food than widely believed: Estimates of global food waste using an energy gap approach and affluence elasticity of food waste. PLoS ONE 2020, 15, e0228369. [CrossRef]

32. Oláh, J.; Zéman, Z.; Balogh, I.; Popp, J. Future challenges and areas of development for supply chain management. LogForum 2018, 14, 127-138. [CrossRef]

33. European Union. Directive (EU) 2018/851 of the European Parliament and of the Council of 30 May 2018 Amending Directive 2008/98/EC on Waste. Available online: https://eur-lex.europa.eu/legal-content/EN/TXT /PDF/?uri=CELEX:32018L0851\&from=EN (accessed on 14 February 2020).

34. European Commission. Commission Delegated Decision (EU) 2019/1597 of 3 May 2019 Supplementing Directive 2008/98/EC of the European Parliament and of the Council as Regards a Common Methodology and Minimum Quality Requirements for the Uniform Measurement of Levels of Food Waste. Available online: https://eur-lex.europa.eu/legal-content/EN/TXT/PDF/?uri=CELEX:32019D1597\&from=en (accessed on 14 February 2020).

35. European Commission. Commission Implementing Decision (EU) 2019/2000 of 28 November 2019 Laying Down a Format for Reporting of Data on Food Waste and for Submission of the Quality Check Report in Accordance with Directive 2008/98/EC of the European Parliament and of the Council. Available online: https://eur-lex.europa.eu/legal-content/EN/TXT/PDF/?uri=CELEX:32019D2000\&from=EN (accessed on 14 February 2020).

36. Kasza, G.; Szabó-Bódi, B.; Lakner, Z.; Izsó, T. Balancing the desire to decrease food waste with requirements of food safety. Trends Food Sci. Technol. 2019, 84, 74-76. [CrossRef]

37. Caldeira, C.; De Laurentiis, V.; Sala, S. Assessment of Food Waste Prevention Actions: Development of an Evaluation Framework to Assess the Performance of Food Waste Prevention Actions; Publications Office of the European Union: Luxembourg, 2019; ISBN 978-92-76-12388-0. [CrossRef]

38. FUSIONS. Report on Review of (Food) Waste Reporting Methodology and Practice. 2014. Available online: http://www.eu-fusions.org/index.php/download?download=7\%3Areport-on-review-of-food-wast e-reporting-methodology-and-practice (accessed on 14 February 2020).

39. Food Loss + Waste Protocol. Available online: https://flwprotocol.org/ (accessed on 3 April 2020).

40. Blair, D.; Sobal, J. Luxus consumption: Wasting food resources through overeating. Agric. Hum. Values 2006, 23, 63-74. [CrossRef]

41. Williams, H.; Wilkström, F.; Ottebring, T.; Löfgren, M.; Gustaffson, A. Reasons for household food waste with special attention to packaging. J. Clean. Prod. 2012, 24, 141-148. [CrossRef]

42. Van Dooren, C.; Janmaat, O.; Snoek, J.; Schnirijnen, M. Measuring food waste in Dutch households: A synthesis of three studies. Waste Manag. 2019, 94, 153-164. [CrossRef] [PubMed]

43. Van Geffen, L.E.J.; van Herpen, E.; van Trijp, H. Quantified Consumer Insights on Food Waste: Pan-European Research for Quantified Consumer Food Waste Understanding. 2017. Available online: https://eu-refresh.org/sites/default/files/REFRESH\%202017\%20Quantified\%20consumer\%20insight s\%20on\%20food\%20waste\%20D1.4_0.pdf (accessed on 2 April 2020).

44. Kunszabó, A.; Szakos, D.; Kasza, G. Food waste-A general overview and possible solutions. Hung. Agric. Res. 2019, 28, 14-19.

45. Szakos, D.; Szabó-Bódi, B.; Kasza, G. Consumer awareness campaign to reduce household food waste based on PLS-SEM behavior modeling. In Proceedings of the 7th International Conference on Sustainable Solid Waste Management, Heraklion Crete Island, Greece, 26-29 June 2019.

46. Doma, E.; Szakos, D.; Kasza, G.; Szabó-Bódi, B.; Bognár, L. Food waste measurement and prevention in Hungarian households. In Proceedings of the 17th Annual STS Conference, Graz, Austria, 7-8 May 2018.

47. Kunszabó, A.; Szabó-Bódi, B.; Szakos, D.; Doma, E.; Kasza, G. Education campaign based on household food waste measurement study. In Proceedings of the Reduce Food Waste Conference on Food Waste Prevention and Management, Vienna, Austria, 25-26 April 2019. 
48. Langley, J.; Yoxall, A.; Heppel, G.; Rodriguez, E.M.; Bradbury, S.; Lewis, R.; Luxmoore, J.; Hodzic, A.; Rowson, J. Food for Thought? A UK pilot study testing a methodology for compositional domestic food waste analysis. Waste Manag. Res. 2010, 28, 220-227. [CrossRef] [PubMed]

49. Kane SP. Post. ClinCalc. Available online: https://clincalc.com/stats/Power.aspx (accessed on 31 March 2020).

50. Rosner, B. Fundamentals of Biostatistics, 7th ed.; Brooks/Cole: Boston, MA, USA, 2011; ISBN 978-0-538-73349-6.

51. Levine, M.; Ensom, M.H. Post hoc power analysis: An idea whose time has passed? Pharmacotherapy 2001, 21, 405-409. [CrossRef]

52. Schott, A.B.S.; Andersson, T. Food waste minimization from life-cycle perspective. J. Environ. Manag. 2015, 147, 219-226. [CrossRef]

53. Patten, M.L. Questionnaire Research: A Practical Guide; Routledge: Abingdon, UK, 2017; ISBN 1936523310.

(C) 2020 by the authors. Licensee MDPI, Basel, Switzerland. This article is an open access article distributed under the terms and conditions of the Creative Commons Attribution (CC BY) license (http://creativecommons.org/licenses/by/4.0/). 